\title{
Research on Principal-agent Problem of Tourism Attractions Development: A Case Study of Kaiping Diaolou
}

\author{
Chunfan Guo ${ }^{1}$ \& Yan Tang ${ }^{1}$ \\ ${ }^{1}$ Management School, Jinan University, Guangzhou, China \\ Correspondence: Yan Tang, Management School, Jinan University, Guangzhou, 510632, China. E-mail: \\ 15521371681@163.com
}

Received: May 3, 2015 Accepted: June 7, 2015 Online Published: July 20, 2015

doi:10.5539/jsd.v8n6p119

URL: http://dx.doi.org/10.5539/jsd.v8n6p119

\begin{abstract}
The value of Kaiping Diaolou as a world heritage site is gradually paid great attention from the public. Meanwhile, how to protect and develop it better becomes an important issue. From the perspective of principal-agent theory, the mode of "trusteeship of property right" (i.e., reserve the ownership to Diaolou of private owners and hand the business management right of Diaolou to the government for centralized management and operation of Diaolou), which is adopted in development of tourism resources of Kaiping Diaolou, is studied in this paper. It is deemed that there are complicated principal-agent relationships existing among the owners of Diaolou, tourism development companies and the local government who participate in the tourism resource development of Kaiping Diaolou, such as bilateral principal-agent with single task, principal-agent with multiple tasks, principal-agent with multiple agents and multi-level principal-agent. Moreover, various principal-agent problems may occur in the further development of tourism resources. Finally, on this basis, the research framework for such kind of problems is put forward.
\end{abstract}

Keywords: tourism resource development, principal-agent, Kaiping Diaolou

\section{Introduction}

Kaiping Diaolou is a type of residential building in Kaiping City, Guangdong Province. Born in a specific historical period (Batto, 2006), it is the integration of Eastern and Western culture, with high historical value, human value and architectural value (Wang, 2012; Zeng et al., 2011). In 2007, Kaiping Diaolou and villages were designated as UNESCO World Heritage Site.

In order to provide better protection for Diaolou, the local government develops the tourism resource of Diaolou properly by adopting the mode of "trusteeship of property right", namely, reserve the ownership to Diaolou of private owners while hand the management right of Diaolou to the government for centralized management and operation of Diaolou. In this way, tremendous benefits have been gained, including not only the necessary funds for maintenance of Diaolou, but also great economic benefits to local communities.

In fact, the principal-agent relationship is formed between the owner of Diaolou and the local government when the owner of Diaolou entrusts the Kaiping Diaolou to the local government. However, due to the different interests of the owner of Diaolou and the local government, during the process of tourism development of Diaolou, the local government, as the manager, may pay more attention to their own interests, such as local economic benefits. The local government may not exactly do what the owner of Diaolou intends to do, so as to deviate from the original intention of the owner of Diaolou. Thus, the principal-agent problem will be caused. To realize sustainable development of Diaolou, the problem mentioned above can be analyzed from the perspective of principal-agent theory.

The core of the principal-agent theory aims at the study of measures taken to induce the principal to take action according to the agent's willingness through contract design in case of interest inconsistency between the principal and agent. The principal-agent theory had its origin in the early twentieth century. At that time, it was mainly used to solve the incentive problem of professional manager in corporate enterprises (Wilson, 1967; Mirrlees, 1974). In order to achieve maximum return, the shareholders need to select a professional manager with professional competence, authorize him/her to operate and manage, and pay him/her. Nonetheless, the shareholders usually fail to monitor all behaviors of the manager all the way; only the final operation results can 
be observed. However, these results are impacted by not only the behaviors of the manager, but also many external factors, such as market factors. Thus, information asymmetry is formed, so the professional manager may do something harmful to the shareholders for his/her own interests. As a consequence, the shareholders shall decide rewards or punishment for the manager in accordance with the observable limited information (such as operating results of the corporate) by designing contracts, so as to inspire him/her to choose the actions that help principals. The principal-agent theory was first used to study the principal-agent problem in the single task (benefit maximization of the corporate) under the sole shareholder (principal) and the sole professional manager (agent). As the social economic relationship become increasingly complex and the research progressed, the scholars discovered that interaction effect between agents would make the original theoretical results inapplicable when there are several agents ((Holmstrom \& Costa, 1986; Demski \& Sappington, 1984; Mookherjee, 1984); and the effort allocation of an agent among multiple tasks would cause new problems when there are multiple tasks (Holmstrom \& Milgrom, 1991; Alderuccio \& Toh,1993). Finally, the research on bilateral principal-agent with single task expanded to principal-agent with multiple tasks, principal-agent with multiple agents and multi-level principal-agent. With the in-depth theoretical study, its application range is also expanding gradually from the foremost salary incentive of enterprise employees to insurance operation (Einav et al., 2011), financial incentive and risk management (Dam \& Koetter, 2012), supply chain management (Wiese \& Toporowski, 2013), agent for franchise right (Gillis et al., 2011), marketing management (Garrett \& Gopalakrishna, 2010; Syam, Hess \& Yang, 2013) and innovation management of scientific research (innovation contests) (Boudreau et al., 2011), etc. However, the theory is rarely used in tourism development at present. The principal-agent relationship in tourism resource development of Kaiping Diaolou is analyzed in this paper from the perspective of principal-agent theory, and the analytical framework for solving the principal-agent problem is put forward on the basis mentioned above.

\section{Brief introduction of Kaiping Diaolou}

Kaiping is located in south central Guangdong Province. In late years of Ming Dynasty, Kaiping was often plagued by bandits and natural disasters, especially flood. In order to guard against the bandits and flood, the local residents began to build a type of high multistory defending architecture in tower shape in the village. This is the earliest Diaolou. In the 1920s and 1930s, the construction of Diaolou reached its climax as a large number of Chinese people who went abroad for a living in early time returned home and purchased properties. At that time, China was in the period of the Republic of China with more frequent wars. In Kaiping, the bandits were especially rampant. For the sake of the safety of families and properties, overseas Chinese built more Diaolou which are suitable for living with their money earned abroad hard. Due to the influence of culture in the country of residence, Diaolou is in various styles and reflects the architectural art in different styles and periods abroad, such as colonnade in Ancient Greece, pillar, arch and vault in Ancient Rome, gothic arch, Islamic arch, components of European castle, arcade of Portuguese style building in Medieval Europe, and European baroque architecture in Renaissance and the 17th century, etc. Diaolou is a perfect combination of oriental and western architectural art, which is not only used for defending and living, but also considered as an important carrier of Chinese history and culture. UNCSCO recognized that Kaiping Diaolou was the symbol of confident, open and compatible attitude of Kaiping citizens when facing advanced cultures (UNESO, 2007). Kaiping Diaolou is with outstanding universal value, which is produced by the overseas Chinese absorbing foreign cultures actively based on their own cultural tradition.

Scattering across towns and villages in Kaiping and spreading for dozens of kilometers, Diaolou present a splendid sight. The large-scale characteristic buildings combining oriental and western architectural style are unique in the world. The number of existing Diaolou is over 1800 in Kaiping. They can be classified into unison building, residential building and watchtower according to various functions, among which the number of residential buildings is the largest. At present, there are 473 unison buildings, 1149 residential buildings and 221 watchtowers. According to different building materials, there are stone building, mansion building, brick building and concrete building, among which the number of concrete buildings is the largest. Now, there are 10 stone buildings, 100 mansion buildings, 249 brick buildings and 1474 concrete buildings (as shown in Table 1). Among them, the most famous buildings are Kaiping Xie Weili Diaolou (Liyuan, Kaiping), Majianglong Village Diaolou Cluster (Majianglong Village), Ruishilou in Jinjiangli village, FangShi Light Tower, Yanping Lou, Risheng Lou and Yiyun Lou. In June, 2001, Kaiping Diaolou was published as one of the key cultural relics protection sites by the State Council. 
Table 1. Classification and quantity of existing Kaiping Diaolou

\begin{tabular}{ccc}
\hline Classification basis & Name & Quantity \\
\hline \multirow{3}{*}{ Function } & Unison building & 473 \\
& Residential building & 1149 \\
& Watchtower & 221 \\
\hline \multirow{3}{*}{ Building materials } & Stone building & 10 \\
& Mansion building & 100 \\
& Brick building & 249 \\
& Concrete building & 1474 \\
\hline
\end{tabular}

\section{Tourism Development and Management Mode of Kaiping Diaolou}

Proper tourism development can provide better protection for Diaolou and present the value of Diaolou to the world at the same time. Nonetheless, the tourism resource development must be supported by the owners of Diaolou. Most of the owners of Diaolou and their families went abroad as immigrants in the last century. Therefore, Diaolou were left alone at home. Some were entrusted to domestic relatives, and some were gradually abandoned. In accordance with the state laws and regulations, Chinese and overseas Chinese holding private real estate have the relevant property rights (Quan-ying, 2011). Although they have lived abroad for quite a long time, the property rights of their Diaolou in China are still in possession of them. To protect and develop Diaolou more effectively, the local government has applied the method of "trusteeship of property right".

The mode of "trusteeship of property right" means that the owners holding the ownership of real estates entrust their real estates to the local government through documents with legal effects, and the local government will fund and manage their real estates, i.e., the local government will manage and develop the tourism resources with full authority after the entrustment from the Chinese and overseas Chinese (Diao, 2007). However, according to the Chinese laws, the local governments are prohibited to get involved with development and operational activities related to Diaolou. Thus, the local government has set up an exclusively-invested state-owned company to be responsible for Diaolou tourism development specially. Through "trusteeship of property right", the right of management and right of operation are separated from the property right structure of tourism resources of Chinese and overseas Chinese, first transferred to the government and then transferred to the tourism development company from the government. Hence, the ownership, right of management and right of operation of Kaiping Diaolou are separated in the property right structure (see Figure 1). 


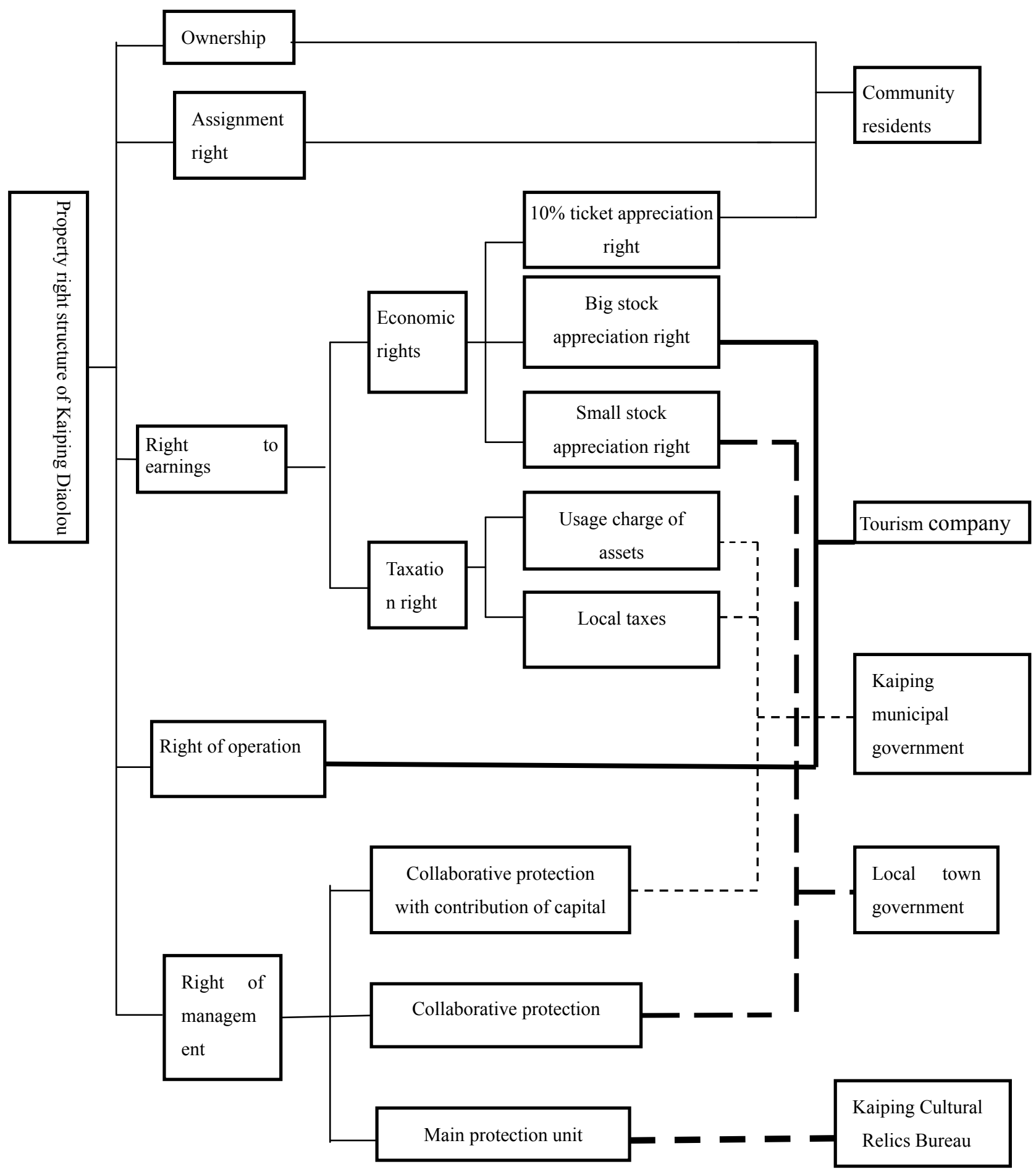

Community residents

-Kaiping Cultural Relics Bureau

Local town government

Tourism company

- - - - - Kaiping Municipal Government

Figure 1. Property right structure of Kaiping Diaolou 
From the property right structure of Diaolou, it can be seen that the ownership of Diaolou belongs to individual residents or village collective. The property right of Diaolou is divided into ownership, right of management, right of operation, right to earnings and assignment right. The residents entrust their Diaolou with tourism value to Kaiping Municipal People's Government. The residents are originally responsible for repair and maintenance of Diaolou. While entrusting Diaolou to the government, their obligations are also entrusted. The residents can get the ticket dividends according to their family sizes. Meanwhile, their exercise of property rights is not restricted. The prerequisite is that they do not violate relevant laws related to tourist resource protection and world heritage, damage the interests of other residents or destroy the unified architecture style of the village. If the residents want to transfer the ownership of Diaolou, they shall obtain the approval of Kaiping Municipal People's Government and report to the Culture Administrative Department of Jiangmen City, Guangdong Province for the record. If a privately owned Diaolou has not been entrusted to the government and the repair and maintenance obligations have not been performed at the same time, Kaiping Municipal People's Government could purchase it according to relevant laws. For the sake of the protection of world heritage, some limits may occur during the implementation of some rights, but the rights of property owners will not be deprived (Ying yang, 2011).

There are similar patterns internationally, such as European castles. As the Kaiping Diaolou, they are also regarded as personal property. The owners shall maintain and develop their castles at their own expense. It needs a large amount of money, which is too hard for many people. Therefore, some owners chose to leave their castles in trust for special research institutions of cultural relic, like The National Trust in England. Independent from the government, it is not only a large institution of historical relics, but also a charity of historical sites and environmental protection. It has been over a hundred years since its establishment. At present, it manages most tourist attractions in England.

\section{Analysis on the Principal-Agent Relationship and Problem in Development and Management of Kaiping Diaolou}

The principal-agent relationship means that one person or some persons (principals) entrust others (agents) to act according to the principals' interests and grant the agents some rights. There are complicated principal-agent relationships existing in the tourism resource development of Kaiping Diaolou, so various principal-agent problems are thus caused.

\subsection{Bilateral Principal-Agent with Single Task}

Bilateral principal-agent with single task refers to the relationship in which there is only one principal, only one agent and only one task. The bilateral principal-agent with single task is the simplest relationship among different kinds of principal-agent relationships, but it is the major principal-agent relationship in the tourism resource development of Kaiping Diaolou. The problem of "moral hazard" would occur under this principal-agent relationship in the tourism resource development of Kaiping Diaolou.

The "moral hazard" refers that principals can impossibly monitor all behaviors of agents due to asymmetric information; thus, in case that difference exists between the interests of the agent and the principal, agents may do behaviors that adversely affect the agents from the view of their own interests. For example, when the owners of Diaolou entrust their business management right of Diaolou to the local government, the owners of Diaolou and the local governments have their different interest demands. For the entrusting of Diaolou, the Chinese and overseas Chinese mainly want to see that their houses and hometown are sound and complete when they return back someday. However, the local government may pay more attention to the local economy development and tax revenue. Thus, the contradiction between development and protection exist between them. In addition, they also have conflicts between development and protection, monopolized operation and local residents' participation in operation. On the other hand, during the process of development of tourism resources, influenced by efforts of operators, society, economy, nature and other aspects, tourism benefits are uncertain; meanwhile, the information asymmetry occurs between the owners of Diaolou and the local government. By contrast, the local government has more information about consumer preference and destination choice of tourists, as well as tourism development planning. Moreover, the owners of Diaolou could not observe the development behaviors of the local government all the time. Therefore, the local government may take various kinds of development methods and choose the suitable effort level of development, so as to realize the benefit maximization. For the local government, it may pay more attention to the local economic interests and take actions against the owners' will in the development of Diaolou. However, the owners of Diaolou may not know the development result of the local government until it becomes an established fact. In consequence, the local government may enhance its own effectiveness at the cost of benefits of Chinese and overseas Chinese. Finally, the problem of moral hazard 
is caused.

\subsection{Principal-Agent with Multiple Tasks}

Principal-agent with multiple tasks relationship refers in which the agent has more than one task or one task involving multiple dimensions. For example, the Chinese and overseas Chinese entrust their real estate to the local government without compensation, in order to develop the tourism resources. On one hand, they hope that the "rented house" can be protected well. On the other hand, they also want to help make their fellow villagers rich through the development of tourism. In this way, their descendants and relatives in hometown can enjoy the benefits of tourism development. Consequently, as the agent, the local government undertakes multiple tasks, mainly three tasks, including task of operation, task of protection and task of getting rich. Task of operation aims to realize maximum tourist income; task of protection aims to effectively protect the real estate and historic culture of overseas Chinese; task of getting rich aims to make the local residents and descendants of overseas Chinese overcome poverty and get rich gradually through the development of tourism. Therefore, under such circumstances, the principal-agent relationship between overseas Chinese and the local government is principal-agent with multiple tasks. On the one hand, in order to pursue its own interests, it is conflicting for the local government to allocate its energy among different works; on the other hand, since the agent runs more than one work, it is also conflicting for the agent to allocate its energy among different works. From the aspect of principals, if different works have different difficulty levels on supervision, excessive incentive on the work easier to supervise will make the agent take excessive efforts on these aspects and ignore others, thus misallocation of resources will be caused ${ }^{[2]}$. Therefore, it is a problem worth considering that how could overseas Chinese supervise and prompt the local government to put more energy on resources protection and make fellow villagers rich.

\subsection{Principal-Agent with Multiple Agents}

When there are several agents, new problems will occur owing to interaction among agents. During the process of development of tourism resources of Kaiping Diaolou, various matters are concerned, including construction, planning, land, real estate management, public security, overseas Chinese affairs, civil administration, tourism, environmental protection, etc. Relevant functional departments participate in the development process of tourism resources, thus to share information on the basis of their complementary advantages, further to realize the team goal. Hence, there are multiple agents for Chinese and overseas Chinese. Owing to the existence of multiple agents, the problem of "free rider" will occur among them, that is, personal behavior of being indolent, or conspiracy problem among the agents. In order to solve such problems, a supervisor (or called principals) should be introduced, thus to arrange optimal entrusted power; in order to avoid conspiracy, Chinese and overseas Chinese should improve the probability of finding conspiracy and prevent conspiracy from happening through the establishment of mechanism.

\subsection{Multi-Level Principal-Agent}

As more and more Diaolou are entrusted by their owners to the local government, massive funds is required for the early repair of Diaolou, so the financial burden of local government becomes heavier and heavier. In order to relieve the financial pressure in protecting Diaolou, the local government uses the method of "adoption", namely, it recruits enterprises or individuals from society to develop and manage the tourism resources owned by Chinese and overseas Chinese by means of lease. For the principal-agent of tourism resource development of Kaiping Diaolou, the right of management is first transferred to the local government and then transferred to enterprises or individuals from the local government; the multi-level principal-agent relationship is thus formed. The multi-level principal-agent relationship makes the information asymmetry even more serious between original principals and ultimate agents, which lead to difficulty in supervision. During the tourism resource development of Kaiping Diaolou, the ultimate agents (tourism development enterprises) may achieve their own goals by taking the opportunity of ineffective supervision, in that the owners of Diaolou fail to supervise the ultimate tourism development enterprises directly. In view of this, the target of operating management may get further away from the target of original principals.

\section{Research on Principal-Agent Problem in Development and Operation of Tourism Resources of Chinese and Overseas Chinese: Frame Construction}

Based on the above analysis, it is necessary to do further researches on the principal-agent problem in tourism resource development of Kaiping Diaolou. On the basis of principal-agent theory, the research framework of principal-agent problem in tourism resource development of Kaiping Diaolou is shown as follows:

Step 1: The features of tourism resources of Diaolou are analyzed. Firstly, the tourism resources of Kaiping 
Diaolou bear the history and culture of Chinese and overseas Chinese. Kaiping Diaolou, a combination of Oriental architecture and Western architecture, reflects fully the inclusiveness of home culture of overseas Chinese and is the historical evidence of Chinese and overseas Chinese accepting the foreign culture actively. Secondly, the tourism resources of Kaiping Diaolou are with high quality and high value of tourism development. Thirdly, unlike other public tourism resources, the property right of Diaolou is clear and most of them are private immovable properties of Chinese and overseas Chinese. These features of Kaiping Diaolou determine that it can be developed on the premise of protection' meanwhile, proper modes should be adopted during the development according to the characteristics of property rights.

Step 2: Principal-agent relationship in the business model is analyzed. In the two modes of "trusteeship of property right" and "adoption", complicated principal-agent relationships, exist in the tourism resource development of Kaiping Diaolou, such as bilateral principal-agent with single task, principal-agent with multiple tasks, principal-agent with multiple agents, multi-level principal-agent, etc.

Step 3: The principal-agent problem in development of tourism resources of Kaiping Diaolou is analyzed. There are different principal-agent problems existing in different principal-agent relationships, such as the major problem of moral hazard in bilateral principal-agent with single task. The incentive problem for different tasks is the main problem for principal-agent with multiple tasks. The incentive problem is regarded as the main problem in principal-agent with multiple agents, and the phenomena of "conspiracy" and "free rider" shall be avoided. For multi-level principal-agent, the problem of inadequate supervision shall be mainly resolved.

Step 4: The incentive restriction mechanism is established. To construct corresponding models for different problems, and put forward relevant incentive restriction mechanism based on the analysis on models. For example, when analyzing the problem of moral hazard, the model of bilateral principal-agent with single task can be established. By signing a contract, the interests of principals can be met when the agents take actions from the view of their own interests. At the same time, the model of principal-agent with multiple tasks can be established for the principal-agent with multiple tasks, and the best incentive effect can be achieved by selecting different incentive intensities for different tasks. For the principal-agent with multiple agents, the models, such as "personal informatization characteristics" and "rank-order tournament", can be adopted, so that different agents may get benefits depending on their final agent behaviors and effects on other agents. Thus, the phenomena of "conspiracy" and "free rider" will be eliminated.

\section{Brief Summary}

During the process of development of tourism resources in China, transferring the operational rights of scenic areas is one of the main modes nowadays, which is a kind of principal-agent relationship in nature. With taking Kaiping Diaolou, the world heritage site, as an example, the principal-agent relationships in tourism resource development of Kaiping Diaolou are analyzed in this paper, and the following conclusions are reached: (1) the essence of "trusteeship of property right" is the separation of the ownership and right of management, and the principal-agent relationship exist with the owner as the principal and the local government as the agent. (2) There are complicated principal-agent relationships existing in "trusteeship of property right", such as bilateral principal-agent with single task, principal-agent with multiple tasks, principal-agent with multiple agents and multi-level principal-agent, etc. (3) Due to the existence of principal-agent relationships, various principal-agent problems, such as "moral hazard", "conspiracy of agents" and inadequate supervision, may occur in the tourism resource development of Kaiping Diaolou. (4) The research framework of principal-agent problems in development of tourism resources is constructed.

\section{Acknowledgments}

This work is supported by Jinan University Management School Funding Program (Study on the Investment Decision-making of Visitors Attraction based on Real Options).

\section{References}

Alderuccio, F., Toh, B. H., Tan, S. S., Gleeson, P. A., \& Van Driel, I. R. (1993). An autoimmune disease with multiple molecular targets abrogated by the transgenic expression of a single autoantigen in the thymus. The Journal of experimental medicine, 178(2), 419-426. Retrieved from http://jem.rupress.org/content/178/2/419.abstract

Batto, P. R. (2006). The Diaolou of Kaiping (1842-1937). Buildings for dangerous times. China Perspectives, (66). Retrieved from http://chinaperspectives.revues.org/1033

Boudreau, K. J., Lacetera, N., \& Lakhani, K. R. (2011). Incentives and problem uncertainty in innovation contests: An empirical analysis. Management Science, 57(5), 843-863. Retrieved from 
http://pubsonline.informs.org/doi/abs/10.1287/mnsc.1110.1322

Dam, L., \& Koetter, M. (2012). Bank bailouts and moral hazard: Evidence from Germany. Review of Financial Studies, 25(8), 2343-2380. Retrieved from http://rfs.oxfordjournals.org/content/25/8/2343.short

Demski, J. S., \& Sappington, D. (1984). Optimal incentive contracts with multiple agents. Journal of Economic Theory, 33(1), 152-171. Retrieved from http://www.sciencedirect.com/science/article/pii/0022053184900450

Diao, M. (2007). Stories Behind the Scenes of Application of Kaiping Diaolou for the List of World Heritage. Chinese Heritage, (6), 94-95.

Einav, L., Finkelstein, A., Ryan, S. P., Schrimpf, P., \& Cullen, M. R. (2011). Selection on moral hazard in health insurance (No. w16969). National Bureau of Economic Research. http://dx.doi.org/10.3386/w16969

Garrett, J., \& Gopalakrishna, S. (2010). Customer value impact of sales contests. Journal of the Academy of Marketing Science, 38(6), 775-786. $\quad$ Retrieved from http://link.springer.com/article/10.1007/s11747-010-0187-4\#page-2

Gillis, W. E., McEwan, E., Crook, T. R., \& Michael, S. C. (2011). Using tournaments to reduce agency problems: The case of franchising. Entrepreneurship Theory and Practice, 35(3), 427-447. Retrieved from http://onlinelibrary.wiley.com/doi/10.1111/j.1540-6520.2011.00438.x/pdf

Holmstrom, B., \& Costa, J. R. I. (1986). Managerial incentives and capital management. The Quarterly Journal of Economics, 835-860. http://dx.doi.org/10.2307/1884180

Holmstrom, B., \& Milgrom, P. (1991). Multitask principal-agent analyses: Incentive contracts, asset ownership, and job design. Journal of Law, Economics, \& Organization, $24-52$. http://dx.doi.org/10.1093/jleo/7.special_issue.24

Mirrlees, J. (1974). Notes on welfare economics, information and uncertainty. Essays on economic behavior under uncertainty, 243-261.

Mookherjee, D. (1984). Optimal incentive schemes with many agents. The Review of Economic Studies, 51(3), 433-446. http://dx.doi.org/10.2307/2297432

Quan-ying, Z. H. U. (2011). Protection of Overseas Chinese House Property: Problems and Solutions. Overseas Chinese History Studies, 2005.

Syam, N. B., Hess, J. D., Syam, N. B., Hess, J. D., \& Yang, Y. (2013). Sales contests versus quotas with imbalanced territories. Marketing Letters, 24(3), 229-244. http://dx.doi.org/10.1007/s11002-012-9211-4

UNESCO(United Nations Educational, scientific and cultural organization. (2007). Kaiping Diaolou and villages.

Wang, S. P., Song, S., \& Liao, X. L. (2012). December. The Research on the Overseas Chinese Local-Style Dwelling Houses Building-Kaiping Watchtowers for Example. Advanced Materials Research, 598, 3-7. http://dx.doi.org/10.4028/www.scientific.net/AMR.598.3

Wiese, A., \& Toporowski, W. (2013). CSR failures in food supply chains-an agency perspective. British Food Journal, 115(1), 92-107. http://dx.doi.org/10.1108/00070701311289894

Wilson, R. B. (1967). The structure of incentives for decentralization under uncertainty (No. 121). Graduate School of Business, Stanford University.

Yang, Y. (2011). Tourism Resources' Exploration and Protection Mechanism On the Basis of Property Right Perspective, Master thesis: Jinan University. 28.

Zeng, Q. G., Zhang, G. X., Tan, J. H., Leung, C. W., \& Zuo, J. (2011). Identification of pigments from the Shrine of Kaiping Diaolou by micro-Raman spectroscopy. Journal of Raman Spectroscopy, 42(6), 1311-1316. http://dx.doi.org/10.1002/jrs.2879

\section{Copyrights}

Copyright for this article is retained by the author(s), with first publication rights granted to the journal.

This is an open-access article distributed under the terms and conditions of the Creative Commons Attribution license (http://creativecommons.org/licenses/by/3.0/). 